Research article

Open Access

\title{
Extracellular localization of galectin-3 has a deleterious role in joint tissues
}

\author{
Audrée Janelle-Montcalm¹, Christelle Boileau ${ }^{1}$, Françoise Poirier², Jean-Pierre Pelletier1, \\ Mélanie Guévremont ${ }^{1}$, Nicolas Duval ${ }^{3}$, Johanne Martel-Pelletier ${ }^{1}$ and Pascal Reboul ${ }^{1}$
}

\author{
1 Unité de Recherche en Arthrose, Centre de Recherche de l'Université de Montréal (CRCHUM), Montréal, Québec, H2L 4M1, Canada \\ 2Universités Paris 6 et Paris 7, Institut Jacques Monod, CNRS UMR 7592, Place Jussieu, 75251 Paris Cedex 05, France \\ 3Pavillon des Charmilles, boulevard des Laurentides, Vimont, Québec H7M 2Y3, Canada \\ Corresponding author: Pascal Reboul, pascal.reboul@umontreal.ca
}

Received: 23 Nov 2006 Revisions requested: 21 Dec 2006 Revisions received: 23 Jan 2007 Accepted: 27 Feb 2007 Published: 27 Feb 2007

Arthritis Research \& Therapy 2007, 9:R20 (doi:10.1186/ar2130)

This article is online at: http://arthritis-research.com/content/9/1/R20

(c) 2007 Janelle-Montcalm et al.; licensee BioMed Central Ltd.

This is an open access article distributed under the terms of the Creative Commons Attribution License (http://creativecommons.org/licenses/by/2.0), which permits unrestricted use, distribution, and reproduction in any medium, provided the original work is properly cited.

\begin{abstract}
In this study we examine the extracellular role of galectin-3 (gal3 ) in joint tissues. Following intra-articular injection of gal-3 or vehicle in knee joints of mice, histological evaluation of articular cartilage and subchondral bone was performed. Further studies were then performed using human osteoarthritic (OA) chondrocytes and subchondral bone osteoblasts, in which the effect of gal-3 (0 to $10 \mu \mathrm{g} / \mathrm{ml}$ ) was analyzed. Osteoblasts were incubated in the presence of vitamin $D_{3}(50 \mathrm{nM})$, which is an inducer of osteocalcin, encoded by an osteoblast terminal differentiation gene. Genes of interest mainly expressed in either chondrocytes or osteoblasts were analyzed with real-time RTPCR and enzyme immunoassays. Signalling pathways regulating osteocalcin were analyzed in the presence of gal-3. Intra-articular injection of gal-3 induced knee swelling and lesions in both cartilage and subchondral bone. On human OA

chondrocytes, gal-3 at $1 \mu \mathrm{g} / \mathrm{ml}$ stimulated ADAMTS-5 expression in chondrocytes and, at higher concentrations ( 5 and $10 \mu \mathrm{g} / \mathrm{ml}$ ), matrix metalloproteinase-3 expression. Experiments performed with osteoblasts showed a weak but bipolar effect on alkaline phosphatase expression: stimulation at $1 \mu \mathrm{g} / \mathrm{ml}$ or inhibition at $10 \mu \mathrm{g} / \mathrm{ml}$. In the absence of vitamin $D_{3}$, type I collagen alpha 1 chain expression was inhibited by $10 \mu \mathrm{g} / \mathrm{ml}$ of gal-3. The vitamin $D_{3}$ induced osteocalcin was strongly inhibited in a dose-dependent manner in the presence of gal-3, at both the mRNA and protein levels. This inhibition was mainly mediated by phosphatidylinositol-3-kinase. These findings indicate that high levels of extracellular gal-3, which could be encountered locally during the inflammatory process, have deleterious effects in both cartilage and subchondral bone tissues.
\end{abstract}

\section{Introduction}

Osteoarthritis (OA) accounts for $40 \%$ to $60 \%$ of degenerative illnesses of the musculoskeletal system. On the whole, approximately $15 \%$ of the population suffers from OA. Of these, approximately $65 \%$ are 60 years of age and over. The high incidence of this illness is rather disturbing since its frequency increases gradually with the aging of the population.

It is well known that age is a primary risk factor for the development of $\mathrm{OA}$, but the mechanisms by which aging contributes to an increased susceptibility to $O A$ are poorly understood [1]. The end point of OA is cartilage destruction, which impairs joint movement and causes pain. In knee joints, the cartilage destruction is associated with and/or preceded by subchondral bone alterations [2]. Joint destruction is also associated with joint inflammation, where the synovial membrane plays a key role [3]. The chronological events of these phenomena are still debated in the literature. However, because of the complexity of the disease, its initiation could occur via any of these tissues, although inflammation of the synovial membrane is less likely to be a primary cause. In OA, it would appear that both cartilage and subchondral bone are altered extracellularly [4-7]. The age-related changes in chondrocytes result in a metabolic and phenotypic decline, triggering chondrocytes to be less responsive to growth factor stimulation and more prone to catabolic stimulation. This 
phenomenon could be the result of biomechanical forces as well as biological sources, such as cycles of hypoxia, the presence of reactive oxygen species, accumulation of advanced glycation end products and the effects of inflammatory cytokines [8-11]. Indeed, clinically detectable joint inflammation may predict a worse radiological outcome in OA [12].

Mechanisms by which synovitis exacerbates structural damage in $\mathrm{OA}$ are complex. Synovitis induces alterations in chondrocyte function and in subchondral bone turnover and enhances angiogenesis $[13,14]$. Cytokines, such as interleukin- $1 \beta$ and tumour necrosis factor- $\alpha$, and growth factors are mainly responsible for these processes. However, another factor, galectin-3 (gal-3), can be markedly present in OA synovial tissue during inflammatory phases, in which leukocyte infiltration occurs [15]. These findings underline the potential deleterious role of gal-3 at the pannus level, where activated macrophages, a type of cell belonging to the leukocyte population able to secrete up to $30 \%$ of their gal-3, are present $[3,16,17]$. This indicates that gal-3 could be found extracellularly in the joint.

The exact role of gal-3 in articular tissues is not yet known. It is a soluble animal lectin of $30 \mathrm{kDa}$ that preferentially recognizes lactosamine and $\mathrm{N}$-acetyllactosamine structures $[18,19]$. Intracellularly, gal-3 is involved in a variety of processes, including RNA splicing [20], differentiation [21], and apoptosis [22]. Extracellularly, it is involved in cell-cell $[23,24]$ or cellmatrix interactions [25-28]. Our recent work reported the capacity of normal and OA human chondrocytes to synthesize gal-3, with an increased expression level in human OA articular cartilage [29].

In the present study, we further investigate the role of extracellular gal-3 in joint tissues. To this end, we first examined its in vivo effect in mice having received an intra-articular injection of gal-3, and further investigated its effect on cells from two OA articular tissues: cartilage and subchondral bone.

\section{Materials and methods Intra-articular injection of galectin-3 in mice}

Six-week-old $129 \mathrm{c} / \mathrm{c}$ mice were housed in wire cages in animal rooms with controlled temperature, humidity, and light cycles. Mice were allowed food and water ad libitum. Recombinant human gal-3 (rh-gal-3) was prepared in our laboratory and sterilized on a $0.2 \mu \mathrm{m}$ filter. As the amino acid sequence of rh-gal-3 shows $85 \%$ identical homology and $91 \%$ positive homology with murine gal-3, we injected rh-gal-3 into the knees of wild-type mice. Mice were distributed into 4 groups receiving $100 \mathrm{ng}, 1 \mu \mathrm{g}$ or $10 \mu \mathrm{g}$ of gal-3 or vehicle (PBS) alone according to previous established protocols [30,31]. After being anaesthetized with isoflurane, a skin incision was performed on each knee and a single injection of gal-3 or PBS administered under the patellar ligament using a Hamilton syringe with a $26 G^{3 / 8}$ intradermal needle. The day of injection was considered day 0 (D0); the animals were sacrificed 4 days after the injection. The study was performed according to the Canadian Council on Animal Care regulations and was approved by the Animal Care Committee of the University of Montreal Hospital Centre.

\section{Knee joint swelling calculation}

Animals were examined daily and knee diameter was measured using a digital calliper (model \#2071M, Mitutoyo Corporation, Kawasaki, Japan) as described by Williams and colleagues [32]. The swelling corresponded to the difference between joint diameter measured every day and joint diameter prior to the injection.

\section{Cartilage histological grading}

Histological evaluation was performed on the sagittal sections of the mouse knees removed at D4. Specimens were dissected, fixed in TissuFix \#2 (Laboratoires Gilles Chaput, Montreal, QC, Canada), decalcified in RDO Rapid Decalcifier for bone (Apex Engineering, Plainfield, IL, USA), and embedded in paraffin. Serial sections $(5 \mu \mathrm{m})$ were stained with safranin $O$ and toluidine blue. The modifications in cartilage and subchondral bone were graded on a scale of 0 to 20 by two blinded, independent observers using a histological scale modified from Mankin and colleagues [33]. This scale was used to evaluate the severity of modifications based on the loss of staining with toluidine blue (scale 0 to 4), cellular changes (scale 0 to 4), surface/structural changes in cartilage (scale 0 to 5), structure of the deep zone of cartilage (scale 0 to 4), and subchondral bone remodelling (scale 0 to 3 ). Scoring was based on the most severe histological changes within each cartilage and subchondral bone section.

\section{Subchondral bone morphometry}

The sections $(5 \mu \mathrm{m})$ of each specimen were subjected to safranin O staining, as previously described [34]. A Leica DMLS microscope (Leica, Weitzlar, Germany) connected to a personal computer (Pentium III, using Image J software, V.1.27, NIH, USA) was used to perform the subchondral bone morphometry analysis. The subchondral bone surface $(\mu \mathrm{m})$ was measured on each slide in two $500 \mu \mathrm{m} \times 250 \mu \mathrm{m}$ boxes, using as the upper limit, the calcified cartilage/subchondral bone junction as previously described [34]. Two measurements were done and averaged for each section.

\section{Human osteoarthritis specimens}

Femoral condyles and tibial plateaus were obtained from 15 OA patients (9 female and 6 male; aged $67 \pm 9$ years) following total knee arthroplasty. All patients were evaluated by a certified rheumatologist and, based on the criteria developed by the American College of Rheumatology Diagnostic Subcommittee for OA [35], were diagnosed as having OA. This procedure was approved by the Ethics Committee of the University of Montreal Hospital Centre. 


\section{Human chondrocyte culture}

Chondrocytes were released from the articular cartilage by sequential enzymatic digestion at $37^{\circ} \mathrm{C}$, as previously described $[36,37]$ and cultured in DMEM (Invitrogen, Burlington, ON, Canada) supplemented with 10\% FBS (Invitrogen) and an antibiotic mixture (100 units $/ \mathrm{ml}$ penicillin base, $100 \mu \mathrm{g} /$ $\mathrm{ml}$ streptomycin base; Invitrogen) at $37^{\circ} \mathrm{C}$ in a humidified atmosphere of $5 \% \mathrm{CO}_{2} / 95 \%$ air. Only first-passage cultured OA chondrocytes were used in the study. OA chondrocytes were seeded at $1 \times 10^{5}$ cells in 12 well plates in DMEM containing $10 \%$ FBS for $48 \mathrm{~h}$; the medium was then replaced for $24 \mathrm{~h}$ by DMEM containing $0.5 \%$ FBS, after which the cells were incubated for $24 \mathrm{~h}$ in fresh media containing $0.5 \%$ FBS in the absence or presence of rh-gal-3 (0 to $10 \mu \mathrm{g} / \mathrm{ml}$ ).

\section{Subchondral bone osteoblast culture}

The overlying cartilage was removed from the tibial plateaus, and the trabecular bone tissue was dissected from the subchondral bone plate. Primary subchondral osteoblasts were released as previously described [38]. Briefly, subchondral bone samples were cut into small pieces of $2 \mathrm{~mm}^{2}$ before sequential digestion in the presence of $1 \mathrm{mg} / \mathrm{ml}$ collagenase type I (Sigma-Aldrich, Oakville, ON, Canada) in DMEM without serum at $37^{\circ} \mathrm{C}$ for 30,30 , and 240 minutes. After being washed with the same medium, the digested subchondral bone pieces were cultured in DMEM containing 10\% FBS. This medium was replaced every two days until cells were observed in the petri dishes. At confluence, cells were passaged once in 12- or 24-well plates in DMEM containing $10 \%$ FBS. Experiments were performed in DMEM containing $0.5 \%$ of charcoaled FBS with or without $50 \mathrm{nM} 1,25[\mathrm{OH}]_{2} \mathrm{D}_{3}(1,25$ dihydroxycholecalciferol; vitamin $\mathrm{D}_{3}$ ) in combination or not with gal-3. To evaluate signalling pathways involved in vitamin $\mathrm{D}_{3}$-stimulated osteocalcin production that are inhibited by gal3 , cells were pre-incubated for $2 \mathrm{~h}$ with specific inhibitors and then incubated for $22 \mathrm{~h}$ in the presence of the inhibitors and vitamin $D_{3}$ in combination or not with gal-3. The inhibitors used were KT5720 (inhibitor of protein kinase A; final concentration $2 \mu \mathrm{M}$ ), KT5823 (inhibitor of protein kinase G; final concentration $2 \mu \mathrm{M}$ ), Genistein (broad inhibitor of tyrosine kinase; final concentration $20 \mu \mathrm{M}$ ), Taxifolin (an antioxidant flavonoid; final concentration $1 \mu \mathrm{M}$ ), wortmannin (inhibitor of phosphatidylinositol 3-kinase (PI 3-kinase); final concentration $250 \mathrm{nM}$ ), PD98059 (inhibitor of mitogen-activated protein kinase kinase-1 (MEK-1) activation; final concentration $10 \mu \mathrm{M})$, and SB202190 (inhibitor of p38 mitogen-activated protein kinase; final concentration $2 \mu \mathrm{M})$. All inhibitors were purchased from Calbiochem (San Diego, CA, USA).

\section{Real time RT-PCR}

RNA extraction and real time RT-PCR were performed as previously described [29]. Primers for the genes encoding a disintegrin and metalloproteinase with thrombospondin type 1 motif (ADAMTS)-5 (aggrecanase-2), matrix metalloproteinase (MMP)-3 (stromelysin), osteocalcin, alkaline phosphatase and type I collagen $\alpha 1$ chain were synthesized by Invitrogen (Table 1). Data analysis was carried out using the Gene Amp 5700 Sequence Detector System software (Applied Biosystem, Foster City, CA, USA) and values normalized to the ribosomal subunit $18 \mathrm{~S}$. Specific primers for type I collagen $\alpha 1$ chain were designed using Primer3 software [39].

\section{Osteocalcin determination}

The assay measured only intact human osteocalcin and was performed on human osteoblast-conditioned media using a specific enzyme immunoassay (EIA) kit with a sensitivity of 0.5 $\mathrm{ng} / \mathrm{ml}$ (Biomedical Technologies Inc., Stoughton, MA, USA).

\section{Protein determination}

Cells were lysed in $0.5 \%$ sodium dodecylsulfate and proteins quantified with the bicinchoninic acid assay [40].

Table 1

\begin{tabular}{|c|c|c|c|}
\hline Amplified gene product & Primers & Base pairs & Reference \\
\hline ADAMTS-5 & $\begin{array}{l}\text { S: GGCATCATTCATGTGACAC } \\
\text { AS: GCATCGTAGGTCTGTCCTG }\end{array}$ & 364 & \\
\hline MMP-3 & $\begin{array}{l}\text { S: GAAAGTCTGGGAAGAGGTGACTCCAC } \\
\text { AS: CAGTGTTGGCTGAGTGAAAGAGACCC }\end{array}$ & 284 & \\
\hline Osteocalcin & $\begin{array}{l}\text { S: CATGAGAGCCCTCACA } \\
\text { AS: AGAGCGACACCCTAGAC }\end{array}$ & 310 & [48] \\
\hline Alkaline phosphatase & $\begin{array}{l}\text { S: TGCAGTACGAGCTGAACAG } \\
\text { AS: TGAAGACGTGGGAATGGTC }\end{array}$ & 267 & \\
\hline Type I collagen $\alpha 1$ chain & $\begin{array}{l}\text { S: CCGAAGGTTCCCCTGGACGA } \\
\text { AS: CGCCCTGTTCGCCTGTCTCA }\end{array}$ & 252 & \\
\hline $18 S$ & $\begin{array}{l}\text { S: GAATCAGGGTTCGATTCCG } \\
\text { AS: CCAAGATCCAACTACGAGC }\end{array}$ & 279 & [29] \\
\hline
\end{tabular}

S, sense; AS, antisense. 
Figure 1

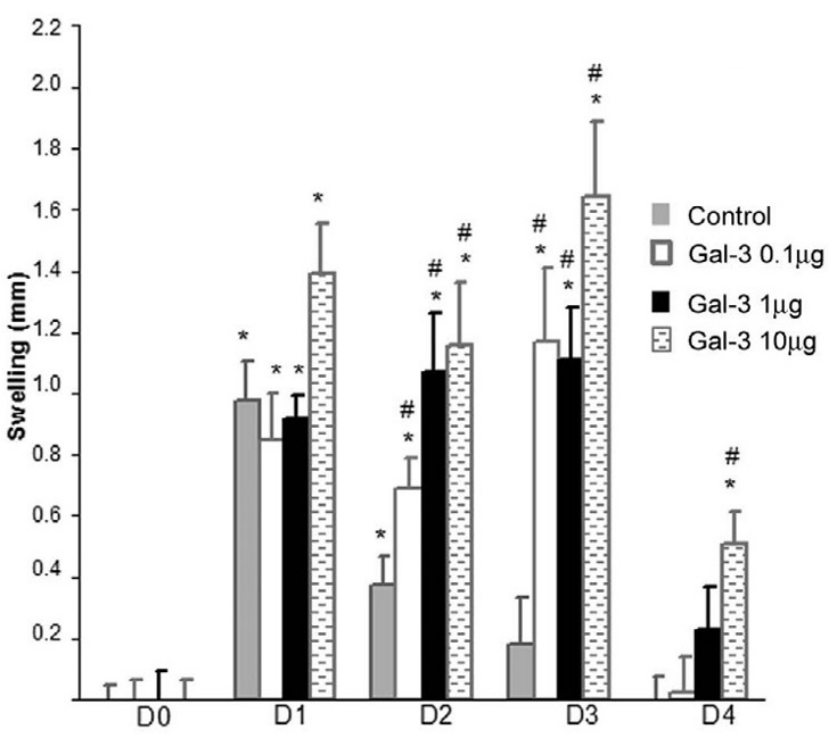

Mouse knee swelling measurement. Galectin-3 (gal-3) was injected in both knees. Animals were examined daily and knee diameter measured using a digital calliper as described in Materials and methods. The swelling corresponded to the difference between joint diameter measured every day and joint diameter prior to the injection (D0). D0 was given the value of 0 . Control (Ctl): injection of PBS. Each group contained four animals. ${ }^{*} p$ versus same conditions as $\mathrm{D} 0 ;{ }^{\#} p$ versus control of the corresponding day.

\section{Statistical analysis}

Data are expressed as mean \pm SEM or median (range). Statistical analyses were the Mann-Whitney $U$ and the two-tailed Student's $t$-tests for animal experiments and cell culture, respectively. Results of $p<0.05$ were considered significant.

\section{Results}

Intra-articular injection of galectin-3

As Ohshima and colleagues [15] showed that gal-3 was markedly present in OA synovial tissues during the inflammatory phase and could be recovered in the synovial fluid, we explored the potential extracellular role of gal-3. We injected gal-3 $(0.1,1$, and $10 \mu \mathrm{g})$ into the knee joints of mice. To evaluate the potential role of gal- 3 in the inflammation process we first determined if this molecule induces joint swelling. Data show that the vehicle alone (control) induced a joint swelling at D1 ( $p \leq 0.0002$ versus D0) (Figure 1). Although joint swelling at D2 was significantly lower compared to D1 $(p<0.005)$, a significant difference was still seen when D2 was compared to DO $(p<0.004)$. Values gradually returned to the basal conditions. Gal-3 exacerbated and extended the swelling; thus, at $\mathrm{D} 2$, gal-3 injections of $0.1,1$, and $10 \mu \mathrm{g}$ significantly induced higher swelling than the vehicle alone $(p<0.05, p<0.004$ and $p<0.002$, respectively). This effect was sustained the third day post-injection $(p<0.006$ for $0.1 \mu \mathrm{g}, p<0.002$ for 1 $\mu \mathrm{g}, p<0.0001$ for $10 \mu \mathrm{g})$. Finally, at D4, values tended to return to those of the control group, although gal-3-induced joint swelling was still statistically significant $(p<0.006)$ with
Figure 2
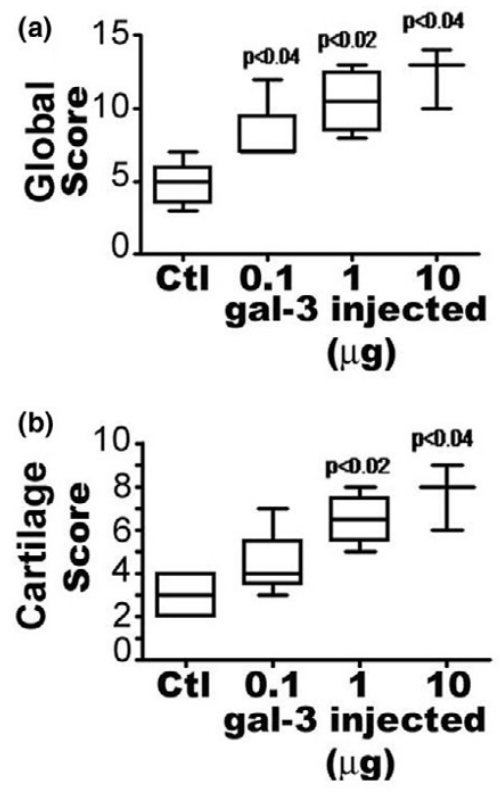

(c)

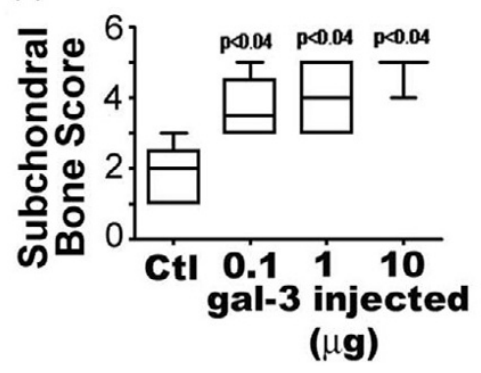

Histological score for mice four days after intra-articular galectin-3 (gal3) injection. (a) Total score, (b) cartilage score and (c) bone histomorphometric score. Data are expressed as median and (range) and are presented in box plot, where the boxes represent the 1st and 3rd quartiles, the line within the box represents the median, and the lines outside the box represent the spread of the values. Control (Ctl): mice injected with PBS. $P$ versus control group; $n=$ four animals per group.

Furthermore, we investigated the effect of gal-3 on cartilage and subchondral bone using histological means. The global histological score (median and (range)) in the control group was 5.0 (3.5 to 6.0) whereas it reached 9.5 (7.0 to 12.5) ( $p<$ 0.04 versus control), 10.5 (8.5 to 12.5$)$ ( $p<0.02$ versus control) and 13 ( $p<0.04$ versus control) in the gal-3-injected group with $0.1,1$, and $10 \mu \mathrm{g}$ gal-3, respectively (Figure $2 \mathrm{a}$ ). The cartilage score in the control group was 3.0 (2.0 to 4.0) whereas it reached 4.0 (3.5 to 5.5), 6.5 (7.5 to 5.5) $(p<0.02$ versus control) and 8 ( $p<0.04$ versus control) in the gal-3injected group with $0.1,1$, and $10 \mu \mathrm{g}$ gal-3, respectively (Figure $2 \mathrm{~b}$ ). The subchondral score in the control group was 2.0 (1.0 to 2.5) whereas it reached 3.5 (3.0 to 4.5) ( $p<0.04$ versus control), 4.0 (3.0 to 5.0 ) ( $p<0.04$ versus control) and 5 ( $p<0.04$ versus control) in the gal-3-injected group with 0.1 , 1 , and $10 \mu \mathrm{g}$ gal-3, respectively (Figure $2 \mathrm{c}$ ). Therefore, both 
Figure 3
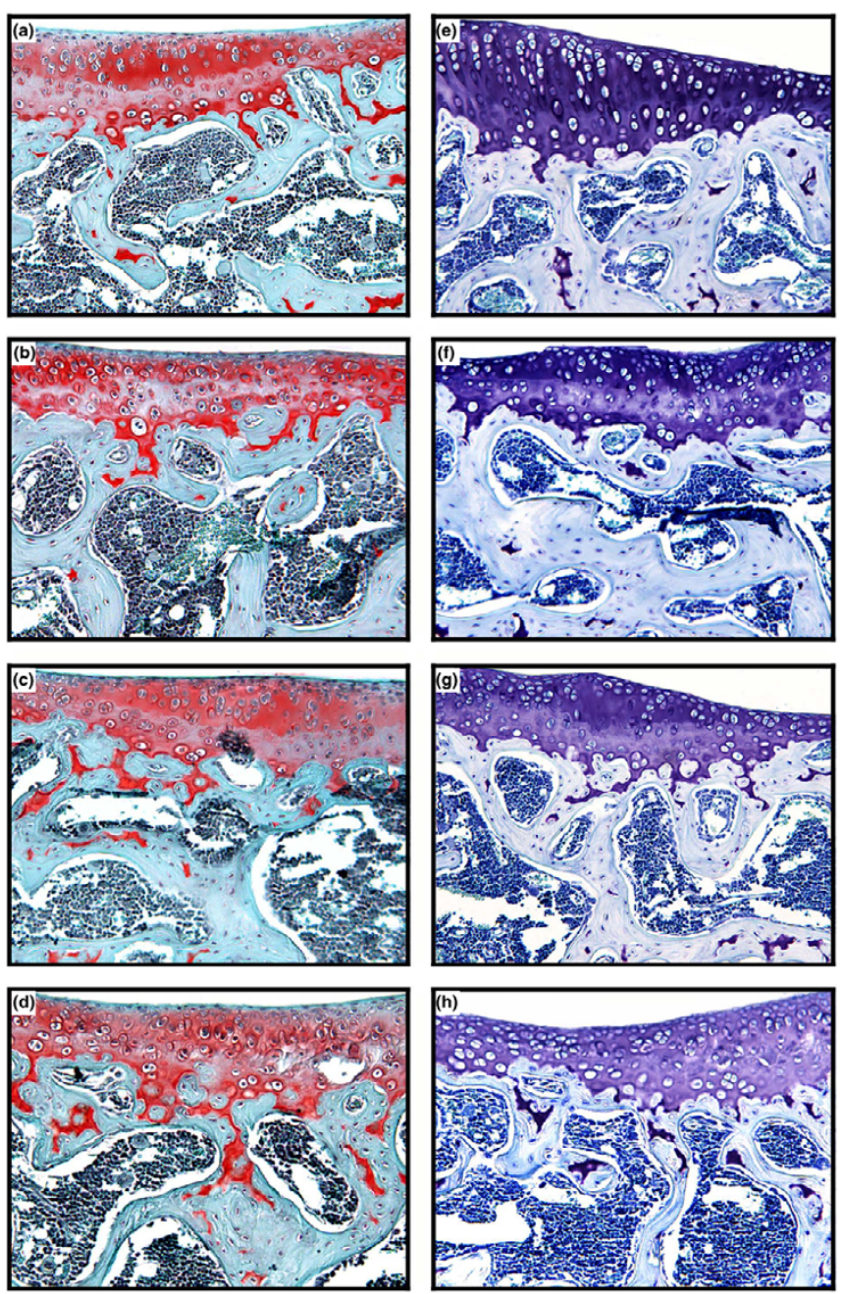

Representative histological sections of specimens from mice stained with (a-d) safranin $\mathrm{O}$ or $(\mathrm{e}-\mathrm{h})$ toluidine blue (magnification $\times 100)$. Control group $(\mathrm{a}, \mathrm{e})$. Mice were injected with $0.1 \mu \mathrm{g}(\mathrm{b}, \mathrm{f}), 1 \mu \mathrm{g}(\mathrm{c}, \mathrm{g})$, or 10 $\mu \mathrm{g}(\mathrm{d}, \mathrm{h})$ galectin-3.

the cartilage parameters (structure/surface, cellularity, and toluidine blue staining) and the subchondral bone surface were modified by the gal-3 injection (Figure 3 ). These modifications are illustrated in Figure 3 , which shows changes in the surface, in cellularity and remodelling of the deep layers in the presence of gal-3 (left panel (b-d)) compared to the control group. Destaining and modification of cell columns were also noticed in the presence of gal-3 (left panel $(f-h)$ ) compared to the control group.

\section{Effects of galectin-3 on chondrocytes and osteoblasts}

Effect of galectin-3 on ADAMTS-5 and MMP-3 in human

$\mathrm{OA}$ chondrocytes

In vivo data strongly suggest that extracellular gal-3 affects both chondrocytes and osteoblasts. We therefore further explored the effects of gal-3 on human OA cells and examined enzymes and markers of these cells. For chondrocytes, two major enzyme systems were evaluated: ADAMTS-5 and MMP3. Data show that human OA chondrocytes incubated with rhgal-3 for $24 \mathrm{~h}$ increased ADAMTS- 5 expression in a biphasic mode. Indeed, it is interesting to note that this gene is very sensitive to gal-3 since a concentration as low as $0.25 \mu \mathrm{g} / \mathrm{ml}$ is sufficient to significantly enhance its expression. Another peak of stimulation was obtained with a concentration of $5 \mu \mathrm{g} /$ $\mathrm{ml}$ (Figure 4). MMP-3 expression was only slightly induced at low concentration and significance was reached at $5 \mu \mathrm{g} / \mathrm{ml}$ with a major increase obtained at $10 \mu \mathrm{g} / \mathrm{ml}$ (Figure 4).

Effects of galectin-3 on osteoblastic markers in human OA subchondral bone osteoblasts

The effects of gal-3 on human osteoblasts were evaluated in the presence or absence of vitamin $D_{3}$, which allows the terminal differentiation of these cells. Alkaline phosphatase expression was increased with gal-3 at $1 \mu \mathrm{g} / \mathrm{ml}(p<0.04)$, but not at $10 \mu \mathrm{g} / \mathrm{ml}$ (Figure 5a). In contrast, the latter concentration triggered significantly lower alkaline phosphatase expression than $1 \mu \mathrm{g} / \mathrm{ml}(p<0.04)$. Alkaline phosphatase, which is upregulated by vitamin $D_{3}$, tended to be increased with gal-3 at $1 \mu \mathrm{g} /$ $\mathrm{ml}(p<0.07)$. A significant difference in alkaline phosphatase expression was found between osteoblasts treated with vitamin $D_{3}$ in the presence of $1 \mu \mathrm{g} / \mathrm{ml}$ gal-3 and vitamin $D_{3}$ in the presence of $10 \mu \mathrm{g} / \mathrm{ml} \mathrm{gal}-3(p<0.03)$.

As previously described, in the absence of vitamin $D_{3}$, osteocalcin expression was maintained at a minimal level, and gal-3 had no effect on osteocalcin expression (Figure 5b). In contrast, in the presence of vitamin $D_{3}$, gal-3 induced a dosedependent inhibition of osteocalcin expression. Indeed, vita$\min D_{3}$ alone stimulated a 43 -fold increase in osteocalcin

Figure 4

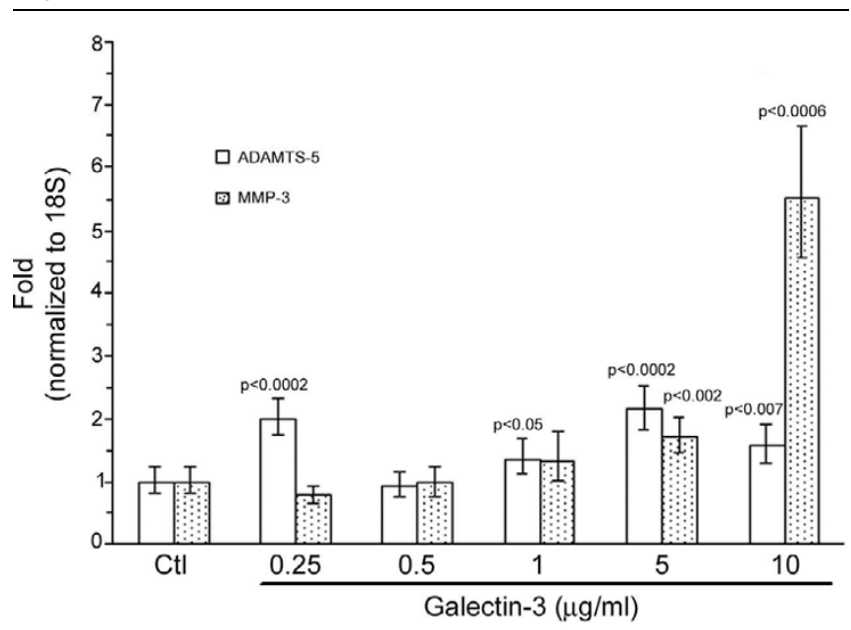

Effects of exogenous galectin-3 (gal-3) on human osteoarthritis chondrocytes. Chondrocytes were treated with increasing concentrations of recombinant human gal-3. Both ADAMTS- 5 and matrix metalloproteinase (MMP)-3 expression were analyzed by real time RT-PCR. $P$ versus control (Ctl); $n=5$. 


\section{Figure 5}

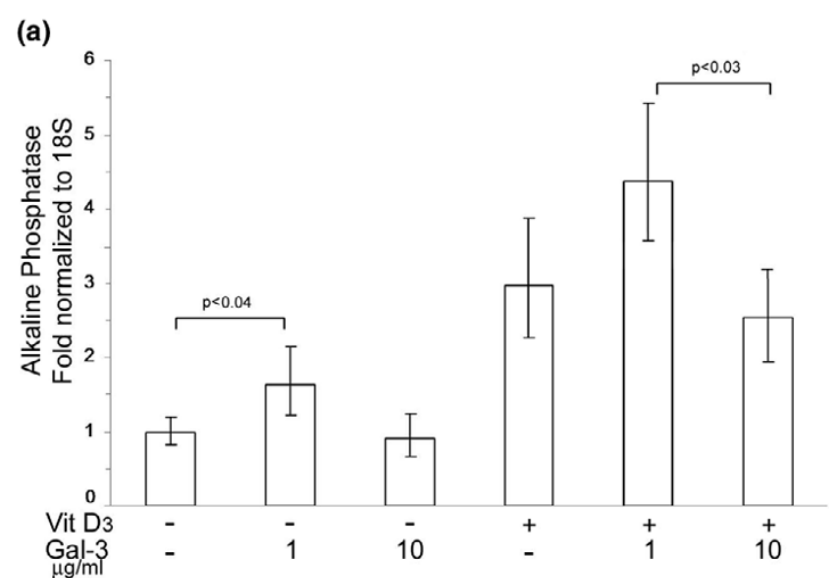

(b)

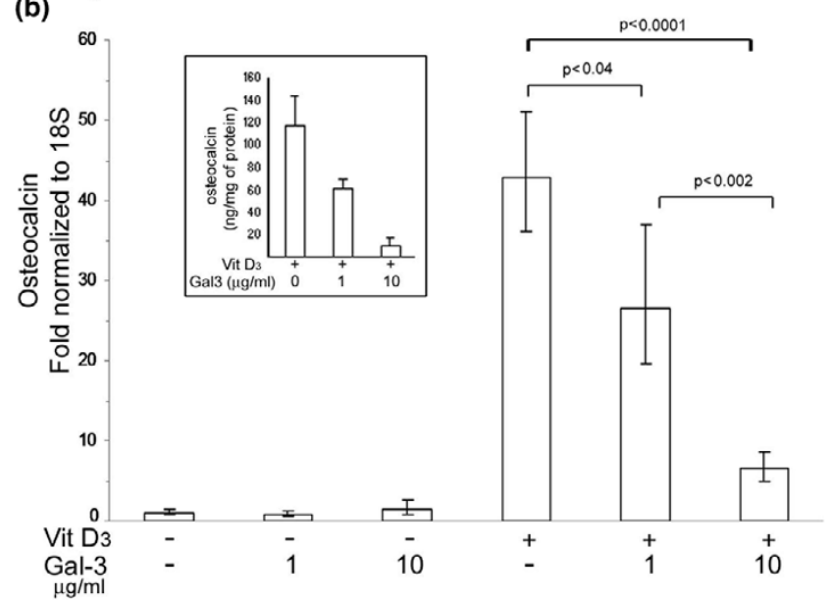

Effects of exogenous galectin-3 (gal-3) on markers of subchondral bone osteoblasts. Osteoblasts were treated with 1 or $10 \mu \mathrm{g} / \mathrm{ml}$ of recombinant human gal-3 in the presence or absence of vitamin $D_{3}$. Both (a) alkaline phosphatase and (b) osteocalcin expression were analyzed by real time RT-PCR. Insert illustrates the protein level of osteocalcin. $N=4$.

expression compared to the basal level, whereas the addition of either $1 \mu \mathrm{g} / \mathrm{ml} \mathrm{gal}-3$ or $10 \mu \mathrm{g} / \mathrm{ml}$ gal-3 with vitamin $D_{3}$ induced osteocalcin expression to only $26.5(p<0.04)$ and $6.5(p<0.0001)$ times the basal level, respectively. These results were confirmed at the protein level by analyzing osteocalcin concentration in conditioned media using an EIA. Osteocalcin production was inhibited by around $40 \%$ and $85 \%$ at gal-3 concentrations of 1 and $10 \mu \mathrm{g} / \mathrm{ml}$, respectively (Figure $5 \mathrm{~b}$, insert). We verified the inhibition of osteocalcin production with a commercially available rh-gal-3 (R\&D Systems, Minneapolis, MN, USA). Results obtained from these experiments were $138.7 \pm 21.2$ (mean $\pm \mathrm{SEM}$; $\mathrm{ng} / \mathrm{mg}$ protein; $n=3$ ) for osteoblasts treated with vitamin $\mathrm{D}_{3}$ alone, $67.6 \pm 7.9$ for those treated with $1 \mu \mathrm{g} / \mathrm{ml}$ rh-gal-3 in the presence of vitamin $D_{3}$ and $2.4 \pm 0.9$ for cells treated with $10 \mu \mathrm{g} / \mathrm{ml} \mathrm{rh-gal}-3$ in the presence of vitamin $D_{3}$. In addition, we made a truncated isoform of gal-3 (Gly108 to lle249) corresponding to the carbohydrate recognition domain (CRD). This truncated isoform is known to be incapable of multimerizing and it is unable to reproduce the effects of whole gal-3. Results obtained with an EIA were $130.2 \pm 16.5$ (mean \pm SEM; ng/mg protein; $n=7$ ) for osteoblasts treated with vitamin $D_{3}$ alone, $158.5 \pm 22.6$ for those treated with $1 \mu \mathrm{g} / \mathrm{ml} \mathrm{CRD}$ in the presence of vitamin $D_{3}$ and $163.4 \pm 26.1$ for those treated with $5 \mu \mathrm{g} / \mathrm{ml} \mathrm{CRD}$ in the presence of vitamin $D_{3}$. As expected, CRD was not able to downregulate the osteocalcin production.

As $10 \mu \mathrm{g} / \mathrm{ml}$ gal-3 almost entirely inhibited osteocalcin production, we further examined the signalling cascades of gal-3 inhibition of vitamin $\mathrm{D}_{3}$-stimulated osteocalcin production with $5 \mu \mathrm{g} / \mathrm{ml}$ gal-3, which resulted in an inhibitory effect closer to $50 \%$ (Figure 6). Vitamin $D_{3}$-stimulated osteocalcin production tended to be inhibited by genistein (35\%) and SB202190 $(40 \%)$, indicating that tyrosine kinases and p38 mitogen-activated protein kinase may be slightly involved (Figure 6). However, the addition of gal-3 in the presence of these inhibitors still induced further inhibition, which was statistically significant ( $p<0.006$ and $p<0.005$, respectively), indicating that gal-3 did not induce these pathways. The combination of gal3 with either KT5720 or KT5823 also significantly inhibited osteocalcin production compared to their respective controls ( $p<0.008$ and $p<0.01$, respectively), indicating that neither protein kinase $A$ nor protein kinase $G$ are involved in gal-3inhibited osteocalcin production. This result was confirmed by the fact that gal-3 alone and gal-3 in the presence of KT5823 did not produce results with a significant difference. In contrast, PD98059 prevented further inhibition of osteocalcin production by gal-3. This result indicates that Erk1/Erk2 kinases are also involved to some extent in gal-3 signalling transduction. Taxifollin, an antioxidant flavonoid, also seemed to prevent gal-3 inhibition of osteocalcin production, but this inhibitor had the weakest effect. The most spectacular result was obtained with an inhibitor of PI 3-kinase, wortmannin, which totally prevented the inhibition of osteocalcin by gal-3.

As type I collagen is the most abundant protein of the osteoid, we finally investigated whether gal-3 affects expression of the type I collagen $\alpha 1$ chain in subchondral bone osteoblasts. In the absence of vitamin $D_{3}, 10 \mu \mathrm{g} / \mathrm{ml}$ of gal-3 inhibited $50 \%$ of type I collagen $\alpha 1$ chain expression $(p<0.02)$ but this inhibitory effect was partly reversed by vitamin $D_{3}$ (Figure 7 ).

\section{Discussion}

In the present study, we show that extracellular gal-3 induced swelling and OA-like lesions in the knee joints of mice. These findings were confirmed by the experiments in which we demonstrated in human OA chondrocytes that gal-3 stimulated the expression of ADAMTS-5 and MMP-3, the main enzymes involved in proteoglycan degradation in cartilage. Furthermore, using human osteoblasts, we showed that gal-3 inhibited osteocalcin production, which is encoded by the most specific and latest gene expressed by differentiated osteoblasts. 
Figure 6

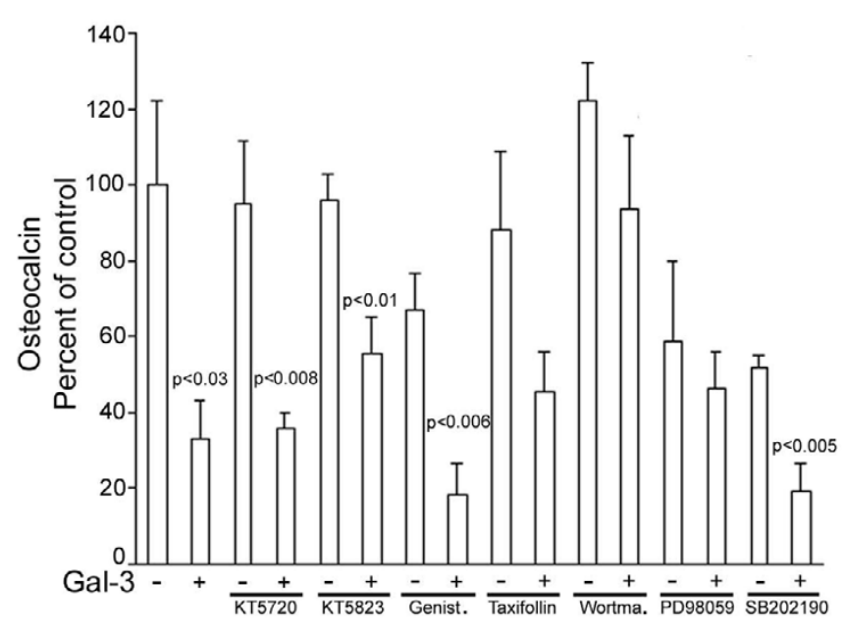

Signalling pathways of inhibition by galectin-3 (gal-3) of vitamin $D_{3}-$ stimulated osteocalcin production. Osteoblasts were treated with $5 \mu \mathrm{g} /$ $\mathrm{ml}$ of recombinant human gal-3 in the presence of vitamin $\mathrm{D}_{3}$ and osteocalcin was determined. Inhibitor concentrations were: KT5720, $2 \mu \mathrm{M}$ KT5823, $2 \mu \mathrm{M}$; Genistein (Genist.), $1 \mu \mathrm{M}$; Taxifollin, $1 \mu \mathrm{M}$; wortmannin (Wortma.), $250 \mathrm{nM}$; PD98059, $10 \mu \mathrm{M}$; and SB202190, $2 \mu \mathrm{M}$. * $P$ versus the autologous control; $n=5$.

Results obtained by Ohshima and colleagues [15] demonstrated that intra-articular production of gal-3 could occur in joints even during $\mathrm{OA}$, and particularly during inflammatory phases. Very often, these phases lead to hyperplasia of the synovium, which may invade the joint space and adhere to cartilage, generating a pannus. This pannus is composed of very active cells such as leukocytes and, most importantly, macrophages, which are able to secrete high levels of gal-3 when they are activated. Therefore, we injected gal-3 into the knee joints of mice and evaluated the structural changes. We found that gal-3 induced a swelling that was sustained compared to injection of PBS alone. Moreover, gal-3 injection generated lesions that affected both cartilage and subchondral bone tissue.

It is interesting to note that two major enzymes responsible for proteoglycan degradation were stimulated by gal-3. This finding corroborates the in vivo data, in which cartilage presented with both alterations and fainter staining with toluidine blue in gal-3 injected mice. However, not all MMPs were stimulated by gal-3 in chondrocytes, since collagenase-3 (MMP-13) was unaffected (data not shown). In addition, the level of tissue inhibitor of MMP-1 (TIMP-1), a natural protein inhibitor produced by chondrocytes, also remained stable (data not shown). We show that ADAMTS-5 was more sensitive than MMP-3 to gal-3, since its expression was stimulated with very low concentrations of gal-3, unlike MMP-3, which required higher concentrations for stimulation. The regulation of ADAMTS-5 is crucial since it was recently demonstrated by two independent groups (using knock-out mouse models) that ADAMTS-5 is the major aggrecanase responsible for prote-
Figure 7

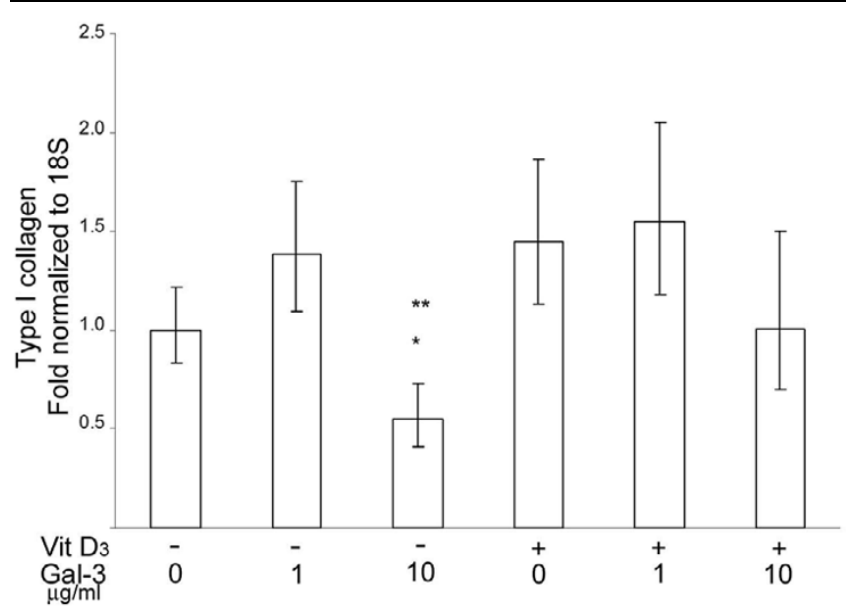

Effects of exogenous galectin-3 (gal-3) on type I collagen expression in osteoblasts. Osteoblasts were treated with 1 or $10 \mu \mathrm{g} / \mathrm{ml}$ of recombinant human gal-3 in the presence or not of vitamin $D_{3}$. Collagen type I $\alpha 1$ chain expression was analyzed by real time RT-PCR. * $P$ versus control (Ctl; without vitamin D3 or gal-3); ${ }^{* *} p$ versus $1 \mu \mathrm{g}$ gal-3 alone; $n=$ 4.

oglycan degradation in cartilage destruction [41,42]. On the other hand, we so far have no explanation for the rebound phenomenon observed for ADAMTS-5 stimulation with $1 \mu \mathrm{g} /$ $\mathrm{ml} \mathrm{gal-3.}$

Gal-3 not only modulated chondrocyte-expressed genes but also those of osteoblasts. More particularly, production of osteocalcin, which is an osteoblastic marker [43], was strongly inhibited by gal-3. Furthermore, the multimerization of gal-3 is needed to induce this effect since the CRD, which is a truncated isoform of gal-3 lacking this property, has no effect. The membranous target recognized by gal-3 is still unknown in osteoblasts. However, among other targets, gal-3 is able to bind integrin $\beta 1$. Interestingly, a recent study reported that the downregulation of integrin $\beta 1$ with either small interfering RNA or blocking antibodies decreased the vitamin $D_{3}$-stimulated osteocalcin level [44]. One hypothesis is that gal-3 may act, at least partially, by blocking integrin $\beta 1$ at the osteoblast surface. Among different cascades of regulation involved in the inhibition of vitamin $D_{3}$-stimulated osteocalcin levels, the PI 3-kinase appears to be a key enzyme. This could be related to the implication of integrins, since it has recently been shown that several biological functions of osteoblasts are regulated via the integrin/PI 3-kinase pathway $[45,46]$.

Unlike osteocalcin, type I collagen $\alpha 1$ chain expression was downregulated only with a high gal-3 concentration. However, vitamin $D_{3}$ prevented the inhibition of type I collagen expression. This latter finding raised the potential role of gal-3 in preventing osteoid matrix formation during the inflammatory process, particularly in individuals with low or depleted levels 
of vitamin $D_{3}$ since it has been shown that vitamin $D_{3}$ analogues have immunomodulatory effects [47].

\section{Conclusion}

The presence of extracellular gal-3 in the vicinity of chondrocytes and osteoblasts causes deleterious effects by both downregulating the anabolic processes and upregulating the catabolic processes. In fact, this factor may participate in cartilage destruction and subchondral bone erosion, particularly during the highly inflammatory phases of $O A$.

\section{Competing interests}

The authors declare that they have no competing interests.

\section{Authors' contributions}

AJM contributed to the in vitro study, analyzed the data and drafted the manuscript. CB participated to the animal study design, analyzed the data and drafted the manuscript. MG participated in the in vitro study. FP, JPP, ND, JMP, PR contributed to the study design. FP, JPP, JMP, PR contributed to the revision of the final manuscript.

\section{Acknowledgements}

The authors thank Virginia Wallis for her assistance in manuscript preparation and Dr Ginette Tardif for designing some of the primers. Christelle Boileau is a recipient of a postdoctoral award from the Canadian Institutes of Health Research/R\&D. Françoise Poirier is a recipient of a Ligue Nationale contre le Cancer grant. Pascal Reboul is a recipient of the New Investigator Award from the Canadian Arthritis Society. This study was supported by grant TAS 01/0033 from the Canadian Arthritis Society and by grant MOP-64401 from the Canadian Institutes of Health Research (PReboul).

\section{References}

1. Loeser RF, Yammani RR, Carlson CS, Chen H, Cole A, Im HJ, Bursch LS, Yan SD: Articular chondrocytes express the receptor for advanced glycation end products: Potential role in osteoarthritis. Arthritis Rheum 2005, 52:2376-2385.

2. Burr DB: The importance of subchondral bone in the progression of osteoarthritis. J Rheumatol Supp/ 2004, 70:77-80.

3. Oehler S, Neureiter D, Meyer-Scholten C, Aigner T: Subtyping of osteoarthritic synoviopathy. Clin Exp Rheumatol 2002, 20:633-640.

4. Verzijl N, DeGroot J, Oldehinkel E, Bank RA, Thorpe SR, Baynes JW, Bayliss MT, Bijlsma JW, Lafeber FP, Tekoppele JM: Agerelated accumulation of Maillard reaction products in human articular cartilage collagen. Biochem J 2000, 350:381-387.

5. DeGroot J, Verzijl N, Wenting-van Wijk MJ, Jacobs KM, Van El B, Van Roermund PM, Bank RA, Bijlsma JW, TeKoppele JM, Lafeber FP: Accumulation of advanced glycation end products as a molecular mechanism for aging as a risk factor in osteoarthritis. Arthritis Rheum 2004, 50:1207-1215.

6. Mansell JP, Tarlton JF, Bailey AJ: Biochemical evidence for altered subchondral bone collagen metabolism in osteoarthritis of the hip. $\mathrm{Br} J$ Rheumatol 1997, 36:16-19.

7. Carrington JL: Aging bone and cartilage: cross-cutting issues. Biochem Biophys Res Commun 2005, 328:700-708.

8. Loeser RF: Molecular mechanisms of cartilage destruction: mechanics, inflammatory mediators, and aging collide. Arthritis Rheum 2006, 54:1357-1360.

9. Kurz B, Lemke AK, Fay J, Pufe T, Grodzinsky AJ, Schunke M: Pathomechanisms of cartilage destruction by mechanical injury. Ann Anat 2005, 187:473-485.

10. DeGroot J, Verzijl N, Bank RA, Lafeber FP, Bijlsma JW, TeKoppele $J M$ : Age-related decrease in proteoglycan synthesis of human articular chondrocytes: the role of nonenzymatic glycation. Arthritis Rheum 1999, 42:1003-1009.

11. Verzijl N, DeGroot J, Ben ZC, Brau-Benjamin O, Maroudas A, Bank RA, Mizrahi J, Schalkwijk CG, Thorpe SR, Baynes JW, et al:: Crosslinking by advanced glycation end products increases the stiffness of the collagen network in human articular cartilage: a possible mechanism through which age is a risk factor for osteoarthritis. Arthritis Rheum 2002, 46:114-123.

12. Ledingham J, Regan $M$, Jones $A$, Doherty $M$ : Factors affecting radiographic progression of knee osteoarthritis. Ann Rheum Dis 1995, 54:53-58.

13. Pelletier JP, Martel-Pelletier J, Abramson SB: Osteoarthritis, an inflammatory disease: potential implication for the selection of new therapeutic targets. Arthritis Rheum 2001, 44:1237-1247.

14. Walsh DA: Angiogenesis in osteoarthritis and spondylosis: successful repair with undesirable outcomes. Curr Opin Rheumatol 2004, 16:609-615.

15. Ohshima S, Kuchen S, Seemayer CA, Kyburz D, Hirt A, Klinzing S Michel BA, Gay RE, Liu FT, Gay S, Neidhart M: Galectin 3 and its binding protein in rheumatoid arthritis. Arthritis Rheum 2003, 48:2788-2795.

16. Sato $S$, Hughes RC: Regulation of secretion and surface expression of Mac-2, a galactoside-binding protein of macrophages. J Biol Chem 1994, 269:4424-4430.

17. He W, Pelletier JP, Martel-Pelletier J, Laufer S, Di Battista JA: The synthesis of interleukin-1beta, tumour necrosis factor-a and interstitial collagenase (MMP-1) is eicosanoid dependent in human $O A$ synovial membrane explants: Interactions with anti-inflammatory cytokines. J Rheumato/ 2002, 29:546-553.

18. Raimond J, Zimonjic DB, Mignon C, Mattei M, Popescu NC, Monsigny M, Legrand A: Mapping of the galectin-3 gene (LGALS3) to human chromosome 14 at region 14q21-22. Mamm Genome 1997, 8:706-707

19. Kadrofske MM, Openo KP, Wang JL: The human LGALS3 (galectin-3) gene: determination of the gene structure and functional characterization of the promoter. Arch Biochem Biophys 1998, 349:7-20.

20. Dagher SF, Wang JL, Patterson RJ: Identification of galectin-3 as a factor in pre-mRNA splicing. Proc Natl Acad Sci USA 1995, 92:1213-1217.

21. Bao Q, Hughes RC: Galectin-3 expression and effects on cyst enlargement and tubulogenesis in kidney epithelial MDCK cells cultured in three-dimensional matrices in vitro. J Cell Sci 1995, 108:2791-2800.

22. Yang RY, Hsu DK, Liu FT: Expression of galectin-3 modulates T-cell growth and apoptosis. Proc Natl Acad Sci USA 1996, 93:6737-6742.

23. Kim HR, Lin HM, Biliran $\mathrm{H}$, Raz A: Cell cycle arrest and inhibition of anoikis by galectin-3 in human breast epithelial cells. Cancer Res 1999, 59:4148-4154.

24. Akahani S, Nangia-Makker $\mathrm{P}$, Inohara H, Kim HR, Raz A: Galectin3: a novel antiapoptotic molecule with a functional $\mathrm{BH} 1$ (NWGR) domain of Bcl-2 family. Cancer Res 1997, 57:5272-5276.

25. van den Brule FA, Buicu C, Sobel ME, Liu FT, Castronovo V: Galectin-3, a laminin binding protein, fails to modulate adhesion of human melanoma cells to laminin. Neoplasma 1995, 42:215-219

26. Ochieng J, Leite-Browning ML, Warfield P: Regulation of cellular adhesion to extracellular matrix proteins by galectin-3. Biochem Biophys Res Commun 1998, 246:788-791.

27. Ochieng J, Warfield $\mathrm{P}$, Green-Jarvis B, Fentie I: Galectin-3 regulates the adhesive interaction between breast carcinoma cells and elastin. J Cell Biochem 1999, 75:505-514.

28. Ochieng J, Green B, Evans S, James O, Warfield P: Modulation of the biological functions of galectin-3 by matrix metalloproteinases. Biochim Biophys Acta 1998, 1379:97-106.

29. Guévremont M, Martel-Pelletier J, Boileau C, Liu FT, Richard M, Fernandes JC, Pelletier JP, Reboul P: Galectin-3 surface expression on human adult chondrocytes: a potential substrate for collagenase-3. Ann Rheum Dis 2004, 63:636-643.

30. van Beuningen $H M$, Glansbeek HL, van der Kraan PM, van den Berg WB: Osteoarthritis-like changes in the murine knee joint resulting from intra-articular transforming growth factor-beta injections. Osteoarthritis Cartilage 2000, 8:25-33. 
31. Jin T, Tarkowski A, Carmeliet $P$, Bokarewa M: Urokinase, a constitutive component of the inflamed synovial fluid, induces arthritis. Arthritis Res Ther 2003, 5:R9-R17.

32. Williams AS, Mizuno M, Richards PJ, Holt DS, Morgan BP: Deletion of the gene encoding CD59a in mice increases disease severity in a murine model of rheumatoid arthritis. Arthritis Rheum 2004, 50:3035-3044.

33. Mankin HJ, Dorfman H, Lippiello L, Zarins A: Biochemical and metabolic abnormalities in articular cartilage from osteoarthritic human hips. II. Correlation of morphology with biochemical and metabolic data. J Bone Joint Surg Am 1971, 53:523-537.

34. Pelletier JP, Boileau C, Brunet J, Boily M, Lajeunesse D, Reboul P, Laufer S, Martel-Pelletier J: The inhibition of subchondral bone resorption in the early phase of experimental dog osteoarthritis by licofelone is associated with a reduction in the synthesis of MMP-13 and cathepsin K. Bone 2004, 34:527-538.

35. Altman RD, Asch E, Bloch DA, Bole G, Borenstein D, Brandt KD, Christy W, Cooke TD, Greenwald R, Hochberg M, et al.: Development of criteria for the classification and reporting of osteoarthritis. Classification of osteoarthritis of the knee. Arthritis Rheum 1986, 29:1039-1049.

36. Reboul P, Pelletier JP, Tardif G, Benderdour M, Ranger P, Bottaro DP, Martel-Pelletier J: Hepatocyte growth factor induction of collagenase 3 production in human osteoarthritic cartilage: involvement of the stress-activated protein kinase/c-Jun $\mathrm{N}$ terminal kinase pathway and a sensitive p38 mitogen-activated protein kinase inhibitor cascade. Arthritis Rheum 2001, 44:73-84.

37. Reboul P, Pelletier JP, Tardif G, Cloutier JM, Martel-Pelletier J: The new collagenase, collagenase-3, is expressed and synthesized by human chondrocytes but not by synoviocytes: A role in osteoarthritis. J Clin Invest 1996, 97:2011-2019.

38. Guévremont M, Martel-Pelletier J, Massicotte F, Tardif G, Pelletier JP, Ranger P, Lajeunesse D, Reboul P: Human adult chondrocytes express hepatocyte growth factor (HGF) isoforms but not HGF. Potential implication of osteoblasts for the HGF presence in cartilage. J Bone Miner Res 2003, 18:1073-1081.

39. Primer3 [http://www.genome.wi.mit.edu/cgi-bin/primer/ primer3 www.cgil

40. Smith PK, Krohn RI, Hermanson GT, Mallia AK, Gartner FH, Provenzano MD, Fujimoto EK, Goeke NM, Olson BJ, Klenk DC: Measurement of protein using bicinchoninic acid. Anal Biochem 1985, 150:76-85.

41. Stanton H, Rogerson FM, East CJ, Golub SB, Lawlor KE, Meeker CT, Little CB, Last K, Farmer PJ, Campbell IK, et al.: ADAMTS5 is the major aggrecanase in mouse cartilage in vivo and in vitro. Nature 2005, 434:648-652.

42. Glasson SS, Askew R, Sheppard B, Carito B, Blanchet T, Ma HL, Flannery CR, Peluso D, Kanki K, Yang Z, et al.: Deletion of active ADAMTS5 prevents cartilage degradation in a murine model of osteoarthritis. Nature 2005, 434:644-648.

43. Eghbali-Fatourechi GZ, Lamsam J, Fraser D, Nagel D, Riggs BL, Khosla S: Circulating osteoblast-lineage cells in humans. $N$ Engl J Med 2005, 352:1959-1966.

44. Wang L, Zhao G, Olivares-Navarrete R, Bell BF, Wieland M, Cochran DL, Schwartz Z, Boyan BD: Integrin beta1 silencing in osteoblasts alters substrate-dependent responses to 1,25 dihydroxy vitamin D3. Biomaterials 2006, 27:3716-2375.

45. Tang CH, Yang RS, Huang TH, Lu DY, Chuang WJ, Huang TF, Fu WM: Ultrasound stimulates cyclooxygenase-2 expression and increases bone formation through integrin, focal adhesion kinase, phosphatidylinositol 3-kinase, and Akt pathway in osteoblasts. Mol Pharmacol 2006, 69:2047-2057.

46. Grigoriou V, Shapiro IM, Cavalcanti-Adam EA, Composto RJ, Ducheyne P, Adams CS: Apoptosis and survival of osteoblastlike cells are regulated by surface attachment. J Biol Chem 2005, 280:1733-1739.

47. Andjelkovic Z, Vojinovic J, Pejnovic N, Popovic M, Dujic A, Mitrovic D, Pavlica L, Stefanovic D: Disease modifying and immunomodulatory effects of high dose 1 alpha $(\mathrm{OH})$ D3 in rheumatoid arthritis patients. Clin Exp Rheumatol 1999, 17:453-456.

48. Rickard DJ, Kassem M, Hefferan TE Sarkar G, Spelsberg TC Riggs BL: Isolation and characterization of osteoblast precursor cells from human bone marrow. J Bone Miner Res 1996, 11:312-324. 